\title{
Freehand Drawing and Architectural Expression
}

\section{Hanif Budiman', Ibrahim Numan², Noor Cholis Idham ${ }^{3}$}

\author{
${ }^{1}$ Architecture Department, Faculty of Architecture And Design, Fatih Sultan \\ Mehmet Vakif University, Istanbul \\ ${ }^{2}$ Architecture Department, Faculty of Architecture And Design, Fatih Sultan \\ Mehmet Vakif University, Istanbul, \\ ${ }^{3}$ Architecture Department, Faculty of Civil Engineering And Planning, \\ Universitas Islam Indonesia, Yogyakarta
}

\author{
Article History \\ Received : 11 February 2021 \\ Accepted : 12 April 2021 \\ Published : 24 April 2021
}

\begin{abstract}
The aspect of expression is very important in design ideas, amidst the pressure of programming and procedural thoughts nowadays. The expression is a performance that was born from the deepening of a strong identity that makes us further involvement. Freehand drawing is believed to be an important activity that cannot be separated from an architectural design process. Freehand drawing is proven to be an effort that will increase awareness to produce creative thoughts that remain logical. The natural and organic character of a freehand drawing with its flexibility will be able to express the unique value of each design idea. It is very different when compared to the stereotypical technical line of mechanics. This paper aims to discuss the role of freehand drawing in improving the quality of expression during the design process. The discussion was carried out through a qualitative descriptive analysis based on the experience of carrying out freehand drawing courses and several freehand drawing learning and practices. The topic of the role of freehand drawing in the digital age is very strategic because it reminds us of the importance of the role of balance cognition for the design process in general.
\end{abstract}

Keywords: design; expression; freehand drawing; identity.

\section{Introduction}

One of the biggest challenges in the architecture world is doing the process of design with awareness carried out with consciousness and providing opportunities for creating critical and creative design ideas. In terms of the design process, how to create deep, creative, even speculative design ideas will be related to graphic thinking and ideation ability by drafting or drawing activities. The drawing was always a determining means of architectural design (Pilsitz, 2017).

It is very interesting to discuss the relationship between freehand drawing and technological developments. Fortunately, thanks to the

Correspondence: Hanif Budiman

Architecture Department, Faculty of Architecture And Design, Fatih Sultan Mehmet Vakif University, Istanbul E-mail: habudiman@uii.ac.id development of tablet technology, the new way of freehand drawing or sketching is increasingly popular. There is so many application for the digital works to expressing sketches, and people can share their digital ideas quickly with others. Further, this digital sketch can be imported into other software, to become the starting point for other work within the design process (Makstutis,2018). Behind the phenomenon of the considerable benefit of the digital technology, especially the effectiveness of design productions, it is realized that basic impact in nowadays situation, are the gap of social and health side, the teamwork culture, the lack of depth critical and creative thinking process and last but not the least is the health of neuro-brain systems and body.

Studying freehand drawing, drafting or sketches could lead to deeper scientific understandings of engineering ideation. Freehand drawing or sketches are interesting also because they are $a$ 
Freehand Drawing and Architectural Expression Hanif Budiman, Ibrahim Numan, Noor Cholis Idham real-time translation of ideas from the cognitive domain to external media and, therefore, could be gateways to observing the cognition behind engineering creativity (Mao, 2019). Sketching itself does not provide the answer (Orthel \& Day, 2016). Practising freehand drawing is still the best way to maintain the mind, the eyes, and the hands in balanced working coordination with the brain, body sensors and feeling like a valuable method of understanding, evaluating and providing imaginative and expressive ideas. Drawing is an example of multi-sensory thoughtful engagement with the world (Mäkelä et al., 2013). Freehand drawing is not just a way to communicate the idea but also offering a way to define the architectural problem and representative solution and identity for architectural expression.

As part of science, especially for an architect, freehand drawing activity will also need to be planned as a way of effective drawing system while accommodating the varied character of people's thinking and uniqueness of expression. The study asks what we can learn from the new science of drawing movements and how new knowledge about cognition, perception and learning may contribute to drawing teaching practice (Brew, 2015).

\section{Research Objectives}

The aim of this research is to examine the values of freehand drawing skill in the architectural design process. By understanding freehand drawing importance and significance, we can develop a systematic method of a freehand drawing learning program to develop the ability in strengthening the architectural expression.

\section{Research Questions}

The main question is why does freehand drawing are recognized to be increasingly needed in the world of architectural education, especially to develop the expression of the design representation. The main question can be continued as follows :

1. How were the types of freehand drawing practices along the design process can develop critically and creatively, the architectural thinking awareness and consciousness, in term to occur architectural design expression?

2. How was freehand drawing practices comprehensively can combining the basic drawing element and aesthetic experimentation to elaborate an architectural expression?

3. How was the freehand drawing, with its special character, can develop along the design thinking process, from the initial phase, analytical, exploration, until the design development phase?

\section{Drawing In Architecture History}

Drawing is a fundamental form of human expression. Prehistoric drawings depicting aspects of early societies, such as hunting scenes, have been found in caves in southern Europe (Moran, 2013). Humans used drawing as a way of expressing their existence. The other earliest type of drawing was also found on the walls of caves in India, China, Australia, South America, even in Celebes in Indonesia. The drawing produced by Neolithic times were eventually stylized and simplified into symbol systems (proto-writing) and eventually into early writing systems. The development of the drawing is founded in early civilizations such as in the Indus valley and Egypt. This idea is a picture symbol or a pictogram, a symbol pattern that has been arranged as a communication language with a certain pattern that implies a certain purpose.

Figure 1. Pictogram Haeroglyph Source: Rowe, 2012

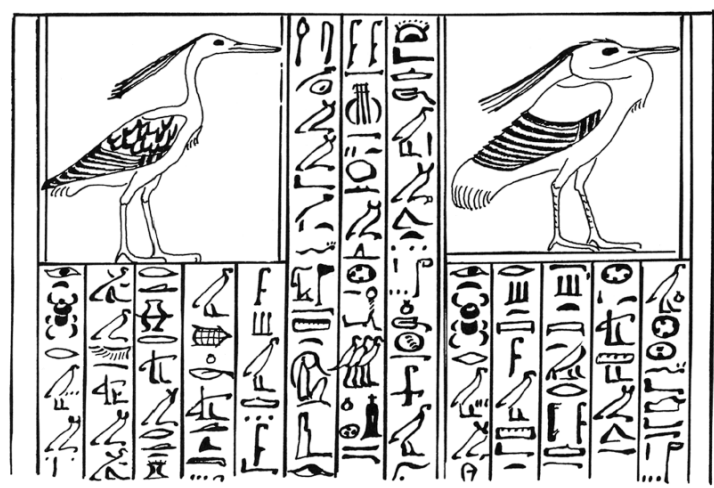

The study of the role of freehand drawing then became very interesting when in the medieval era there were several works emerged that trigger the importance of expressive ideas in design thinking. The two important figures from the medieval era who introduce expression in the drawing are Villard de Honnecourt and Mohamed Siyah Kalem. Villard's sketches are an excellent example in the architectural history of how drawing is an important process in understanding and visualizing expressions. It is very challenging to find sources, especially 
technical drawings of earlier periods, especially in the medieval era. One of the most interesting things about Villard drawing is a very expressionist character.

Figure 2. Villard de Honnecourt Figure Expression Drawing Source: https://gallica.bnf.fr/ark:/12148/btv1b10509412z/ f75.image
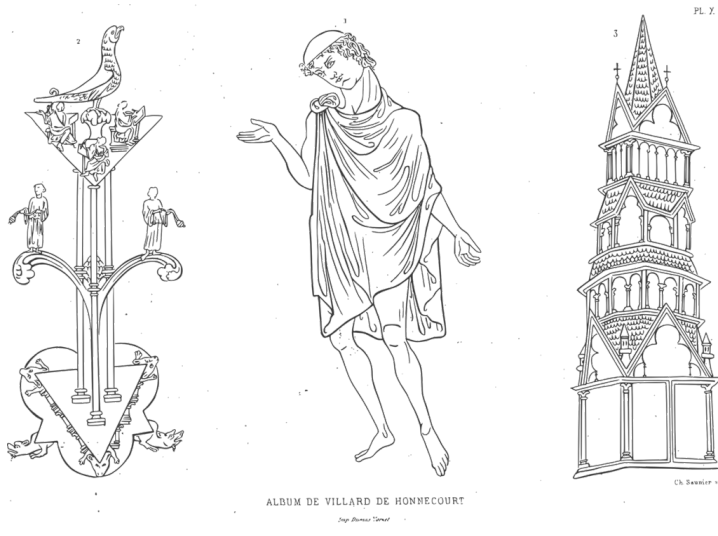

Not only the character expression of several figures but also the expression of form and the spatial system works in the observed building. In his sketches, Villard elaborated through repetition, variation and alternation of graphic and/or figural aspects, the illumination of pages relating to the gospel texts-evangelist portraits which is the main aim of this figure sketches is a visualization of harmony. Villard uses a grid system in the schematic ground plan of a Cistercian church, which shows that he indeed has knowledge of the design process of churches (Pekol, 2005). This is an early effort in perspective and dimension expression of the architectural drawings.

Figure 3. Siyah Kalem Expressive Drawing

Source: Ipsiroglu,1985

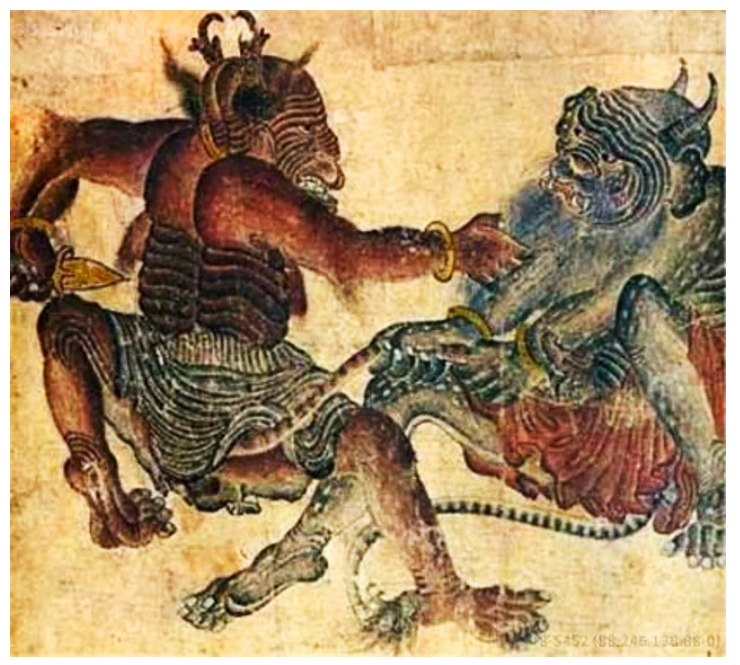

While Mohamed Siyah Kalem, a Turk who lived around Central Asia, was accepted as one of the most expressive and enigmatic drawers from the 15th century. He is an example of how an attempt of expression by the elements in figurative shapes with very dynamic lines character, vivid tonal gradations and the compositions are highly expressive.

Theoretically, the most significant influence in the history of drawing is in the renaissance era, when human existence became the orientation of thought. At this time, drawing came to be considered the foundation for work in all the arts and drawing mandatorily was trained before going on to painting, sculpture, or architecture. An important thought from the renaissance era was the use of perspective principles in giving a realistic effect of an object's composition. This central perspective was invented in Florence in the early fifteenth century (Hoffmann, 2010). It's one of the most powerful moment to make drawing was perceived expressively and felt more realistic style. Then the development of the drawing follows the development of the art and industrial movement at modern time. The architectural drawing was used as a tool for logical thinking. The analysis of architectural forms is performed following a structuralist thought, and it consists in the use of drawing for studying the parts of a building and their relationships (Serra et al., 2015).

\section{Expression In Architecture Design}

The idea of creative architecture by an experimentation architectural aesthetic that privileges drawing as an expressive tool emerged less than a century ago. Aside from the utopian drawings of the eighteenth century - the visionary expressions of Boullee or Ledoux and the unlikely prisons of Piranesi drawing found its true expressive value when space was liberated, and it could become a free domain, an open field (Allen, 2016).

The expression drawings themselves are significant for their strong sense of identity, a presence that says they are important, and we ought to take time to look at them more closely. How does the way the sketches were drawn account for this quality? Both the style and the high contrast are important, but the fluidity of the sketches tells us about the intensity and confidence of the architect. We can almost see or feel the architect's hand moving over the 
paper (Laseau, 2001).

Figure 4. Basic Drawing

Source: Budiman, 2020

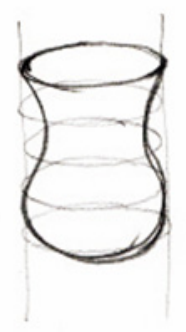

Figure 5. Expression

Source: Budiman,2020

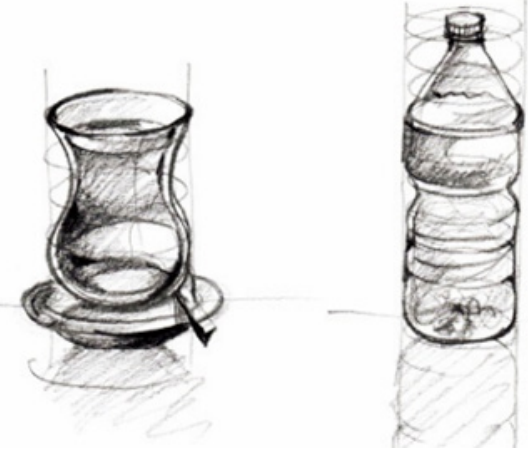

Figure 6. Basic Drawing \& Expression Source: Budiman, 2020

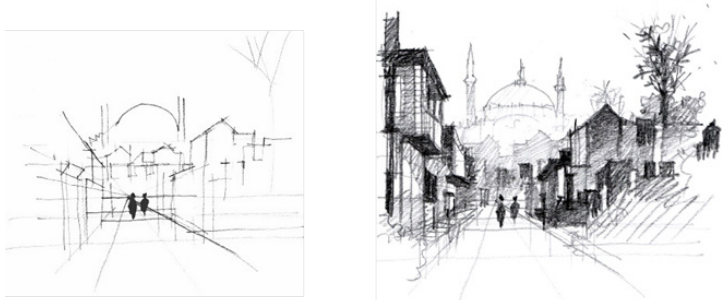

The principle of the expression is the elaboration of the basic elements of drawing such as basic lines, shapes \& form, grid (with its characters), projection, and then sufficiently process an adequate balanced the basis value of an architectural expression or an experimentation architectural aesthetic (depth of spaces, dynamics composition, partly contrast and strong representative identity).

\section{Methodology}

The methodology in this research is developed based on the research objectives to develop a critical and creative freehand drawing method that can produce an expressive architectural design. It will compose the action research methodology as descriptive-collaborative framework research, which is conducted for participants. The research method should allow for an actively involved researcher and be flexible enough to accommodate various modes of action (Herr, 2015). Action research is the application of fact-finding to practical problem-solving in a social situation to improve the quality of action within it. The focus in action research is on a specific problem in a defined context, and it has four basic characteristics, it is situational, collaborative, participatory and self-evaluative. From this action research methodology, there will be able to compile a step procedure, starting from determining the freehand drawing method and selecting respondents who will be escorted to aesthetic experiment with this freehand drawing method.

Figure 7. Freehand Drawing Action Research Methodology Source: Budiman et al., 2020

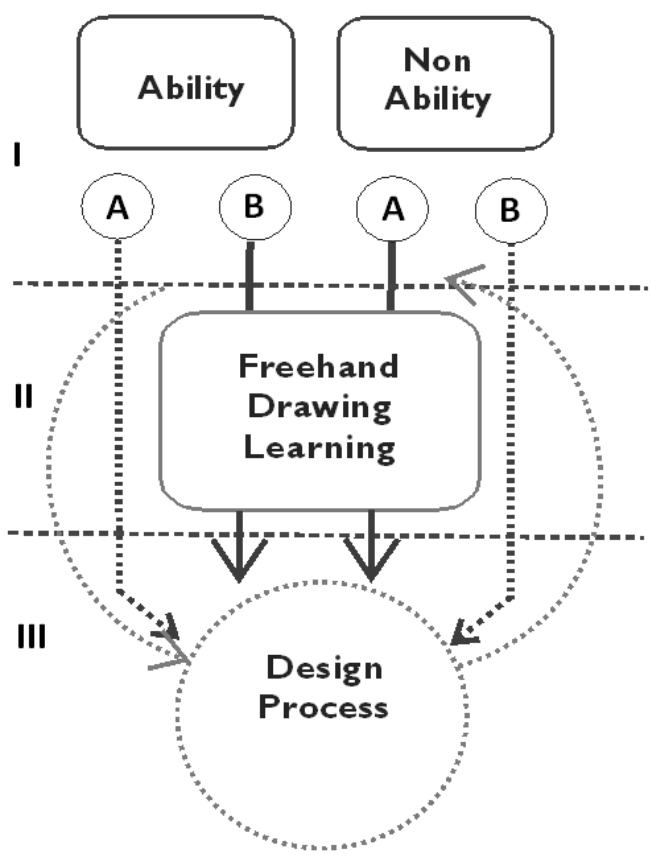

Practically, this methodology will be started by a simple assessment to define the basic ability. The basis for determining this ability is based on the criteria of architectural expression ideas that the sketch tries to convey. Basic geometry, the idea of the arrangement of the space 
elements, and the efforts to display the depth of space with variations of lines are the aspects of the basis of this ability. This does not depend on the character of lines or the accuracy of the shape and dimension of the objects. The procedure of the research methodology is described below.

(I). The class of learning was conducted on two groups, who were separated by basic ability in freehand drawing. The basis of simple ability assessment is not based on the character of the basic element drawing, such as the type of line or geometric shapes or forms. But more on architectural expression idea is there an attempt to process basic elements of the drawing, mainly the line variations, to show contrast values, depth of space and object composition in general.

(II). In each group, half of the respondents will be supervised through methodological assistance, and half of them will be left through the drawing process without methodological supervising or assistance. In this step, respondents will receive freehand drawing learning methods and the practices program and the target of learning activities. The perception, sensation, and movement of existence in this world are not separated (Lee, 2014). Because of that, practices will strengthen the ability to organized the aesthetics perception in term of exploring the architectural expression.

(III). Based on freehand drawing learning methods, students will compose the design process. During the process, collaborative discussions and exchanging ideas were conducted among the participants. It is very important to develop blending learning with program variety, sharing the experiences along with the sketches, and the participant can evaluate together (collaboration in evaluating and creating). The co-creation process carried out has had a positive impact during the development of the tool, allowing to identify the cycles of improvements needed as well as to revise the initial blended learning mode. (Albo \& Hernandez-Leo, 2019).

There is nothing in vain in repeating the practice of lines, for example, even though the design process has gone into the analysis or development stage. The principle of this freehand drawing method is the preparation of the basic elements of drawing and then creatively exploring the expression by aesthetic experimentation. The basic elements of drawing are the lines, shapes \& from, compositions (with its characters), projection. These elements sufficiently will be used to explore architectural expression by an experimentation architectural aesthetic such as characterized lines trial to explore the shapes, form or shape, the partly contrast to explore strong identity, diagrammatic combination to determined unity, or dramatic point of view to search the dramatic visual. This method was shown in the diagram below.

Figure 8. The Method of Freehand Drawing Learning Practises Principles

Source: Budiman et al., 2020

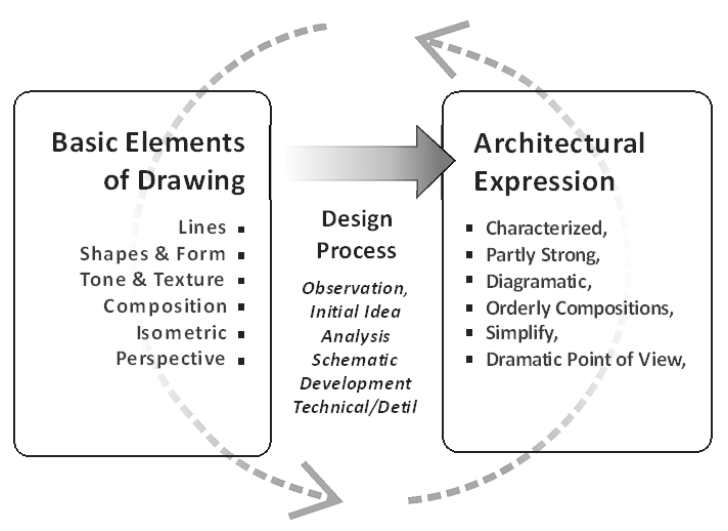

All the experiment practically to find the soul of the design idea or the representative expression such as characterized lines, depth of spaces, dynamics/ orderly composition, partly strong tonal contrast and representative identity.

\section{Result and Discussion 1. Freehand Drawing Application}

Real architecture drawings are not illustrations but pure expression of architectural thinking (Smith, 2005). Regarding the method mention above, the concept of a freehand drawing practises program was developed as follows (Table 1):

Therefore, one of the important things in processing architectural expression thinking is to experiment creatively at various stages of the architectural design process while remaining based on the critical basics of architectural programs. 
Tabel 1. Drawing Practises Program

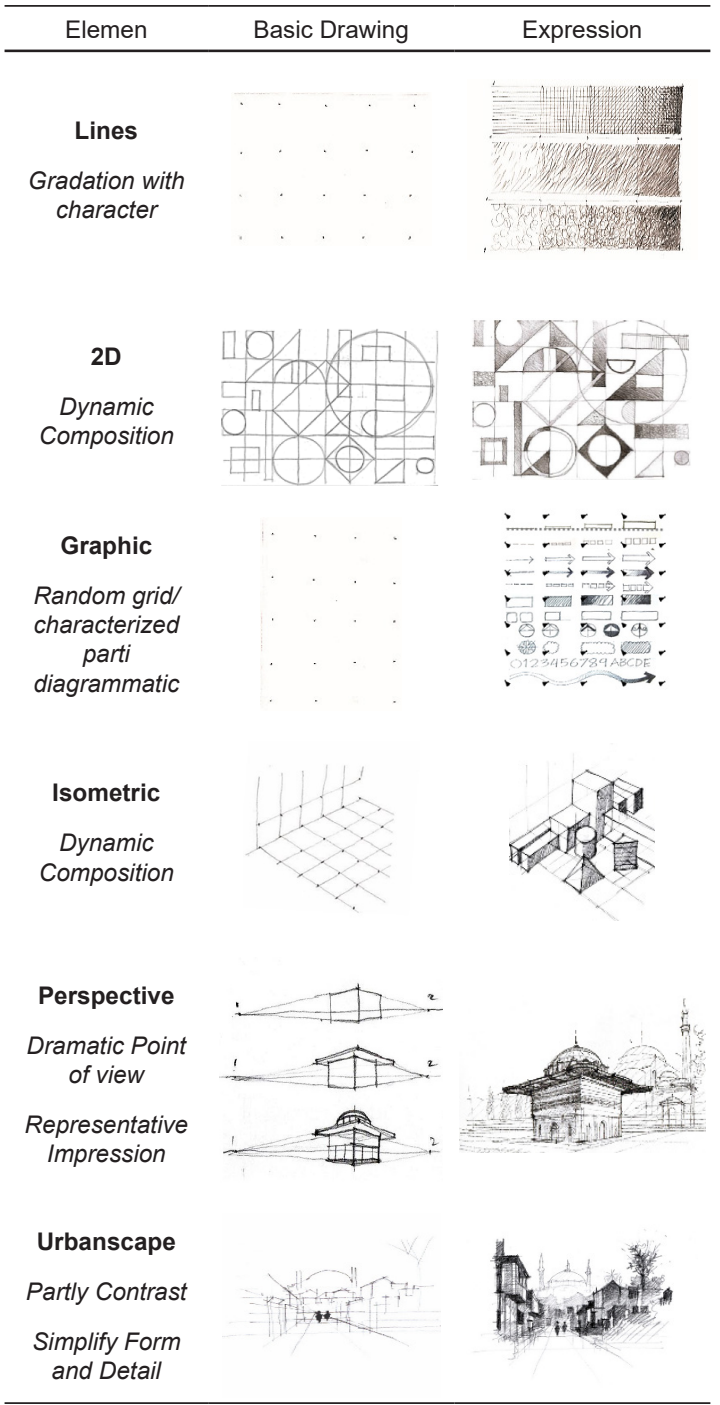

Source: Budiman, 2020

\section{Result}

There are 76 respondents organized in this learning program. The final results generally show that groups with basic abilities will relatively succeed in the design process than the group without abilities. But this is certainly not a guarantee that those who have the freehand drawing ability to succeed only have greater opportunities than those who do not have the talent or ability. From table 1, it can be seen that the basic elements of the image are lines, 2D and 3D shapes and compositions, graphic design, isometry and perspective and urbanscape. Each of these elements has a special way of experimenting to get a strong expression representing the concept object. And this was done in a very varied way by the respondents.

\section{Line}

Respondents tend to explore the lines of relatively the same type and intension or pressure, even though they have a line character. Relatively less varied to develop the potency of the character to express the aesthetic value such as a variation of texture or gradation of tonal value. However, it is seen that there are efforts to maximize the processing of this line to create a logical direction.

\section{D Shapes \& Composition}

Basic geometric shapes are relatively well processed, both basic shapes (squares, circles \& triangles) and developing shapes (rectangles, hexagons, semicircles, etc.). What needs to be developed is the ability to process line variations with various directions, pressures and strokes.

Figure 9. Example of Result of Line and 3D of Freehand Drawing Methods

Source: Budiman, 2020
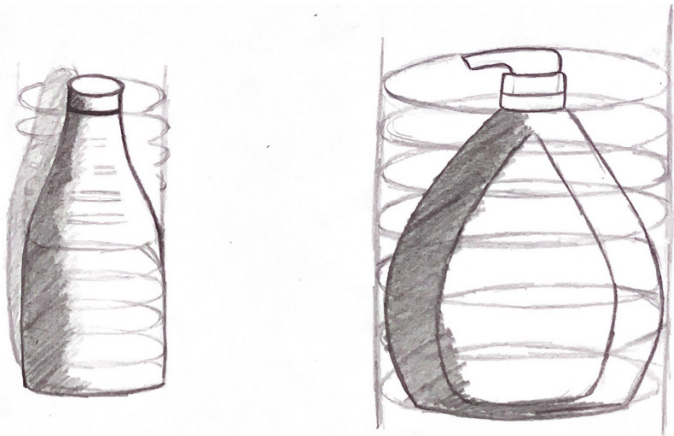

\section{D Shapes \& Composition}

The main objective of this exercise is to work out the composition dynamically. 3D geometric shapes provide more opportunities for alternatives. What needs to be developed is the ability to process line variations with various directions, pressures and strokes.

\section{Graphic Thinking}

The principle of composition is essential here. The basis of the grid, which should provide an opportunity for aesthetic experimentation, is relatively unused for the creative randomy exploration of graphic design ideas. Based on freehand drawing learning and method, respondents arranged a grid to explore the composition of presentation elements, both images and text. The principle of harmonious unity and continuity, as a way of graphic communication. 
Figure 10. Example of Graphic Thinking Result of Freehand Drawing Methods

Source: Budiman, 2020
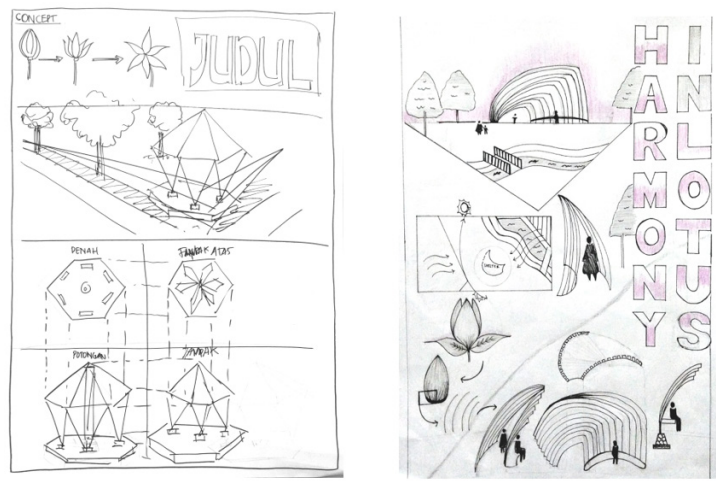

\section{Isometry}

Respondents tend to process isometry with discipline, with strong 3D modules/grids. However, further experiments are still needed so that the composition is dynamic and gets a strong impression. Overall the results are still less varied. However, it is seen that there are efforts to maximize the processing with variations in tones.

\section{Perspective}

Respondents were quite enthusiastic about participating in perspective exercises ranging from horizons to processed experiments with vanishing points. Some of them are still processing perspective ideas in stereotypical ways, just fulfilling the needs of horizons and vanishing points. Not maximally choosing a view angle that produces a dramatic point of view to show a representative impression. However, the expression can be seen from the processed lines, texture and contrast. So that, in general, the expression can still be felt (Figure 11).

In all groups (no ability or ability group), the situation along the freehand drawing learning is clear enough. Sketch exercises that are carried out continuously and consistently on various objects and various forums are proven to produce developing abilities. The design idea along the process is quite creative and cultivates elements varied.

The final results of the freehand drawing method can be shown in the graphic below (Figure 12).
Figure 11. Example of Result of Perspective of Freehand Drawing Methods

Source: Budiman, 2020
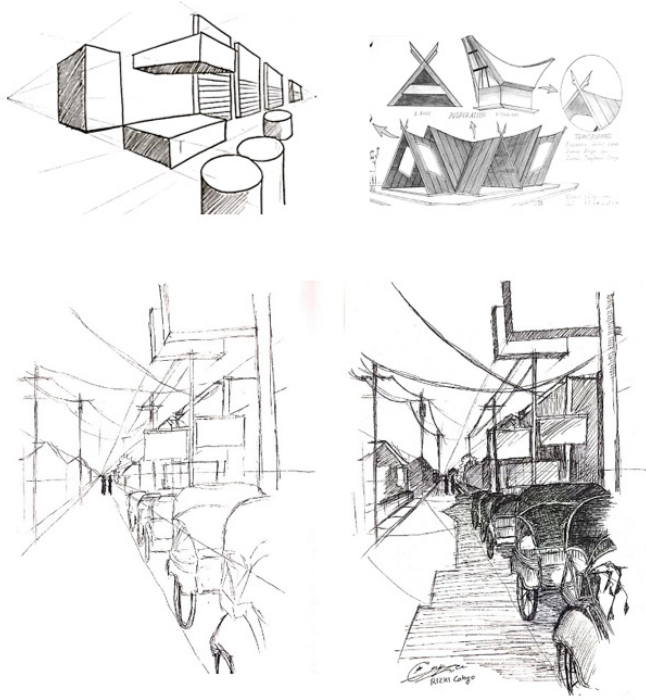

Figure 12. Result of Freehand Drawing Methods

Source: Budiman, 2020

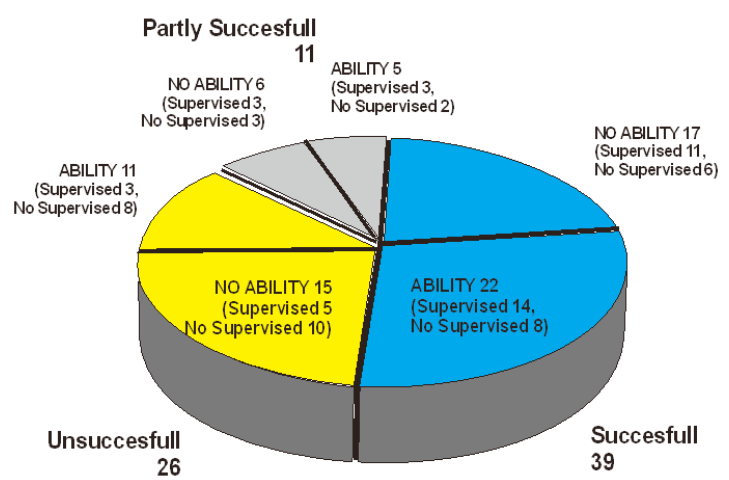

Successful results are shown by processing most of the basic elements of drawing (line, $2 D \& 3 D$ shapes, isometry, graphic thinking and perspective) through expressive freehand drawing experimentations. Meanwhile, those who are not successful do not or only process a few of the basic elements of drawing.

\section{Elaboration The Expression}

Elaborate the expression actually one of the most fundamental aspects of freehand drawing in term of the architectural design process. According to Laseau (2012), the drawing expression will be related to a strong sense of identity. The sketches were drawn account for this quality will be explored by the style and the high contrasting impression. Also, the fluidity of the sketches tells us about the intensity and confidence of the designers. This expression cannot be generated instantly. Repeated 
Freehand Drawing and Architectural Expression Hanif Budiman, Ibrahim Numan, Noor Cholis Idham practice will help strengthen the expression that will result from this freehand drawing learning method. Only a few of all respondents survived the perseverance of the practice. At the beginning of the assessment, several potentials uniquely expressive freehand drawing characters were seen. However, in the subsequent design process, this was relatively difficult to maintain because the mindset that directed stereotypical and technical drawing was still quite dominant.

What is not easy is developing a strong expression through dynamic composition experiments, creative contrast on certain parts of an object, and choosing a dramatic angle point of view in drawing practice using the perspective method. Most of the participants were draw a stereotypical perspective with a symmetrical angle so that it did not show the strength of their design identity. After discussion, an image with a stronger expression was obtained.

From all the discussions in the previous section, it can be concluded that the important elements of drawing that need to be considered in processing freehand drawing practise producing ideas of architectural expression in a design process are as follows (Table 2):

It turned out that it was increasingly difficult to remind and train the respondents in online learning situations. Aesthetic experimentation, which is an important process for bringing out these characters, is relatively difficult to discuss more deeply because active, dialogical and intensive communication cannot be formed due to the limitation of interface communication. Discussions based on only displaying on the monitor are not flexible enough to produce interactive discussions. Sharing of experiences and a few different points of view of the arguments are very important. Cognitive conflict arises from the different views and opinions of collaborators. The authors stated that the production of creative outputs requires constructive disagreement rather than mainly congruent opinions (Hong et al., 2016)
Tabel 2. Expression Elements

\begin{tabular}{|c|c|c|}
\hline Basi & Drawing & Expression \\
\hline Observation & $\begin{array}{l}\text { - Gesture sketches } \\
\text { - Graphic elements }\end{array}$ & $\begin{array}{l}\text { - Characterized sketch's } \\
\text { \& Typography }\end{array}$ \\
\hline Analysis & $\begin{array}{l}\text { - Diagram/parti } \\
\text { - Graphic elements }\end{array}$ & $\begin{array}{l}\text { - Characterized sketch's } \\
\text { \& Typography } \\
\text { - Basic composition }\end{array}$ \\
\hline Basic Idea & $\begin{array}{l}\text { - Diagram/parti } \\
\text { - Basic Geometric } \\
\text { - Flexible lines }\end{array}$ & $\begin{array}{l}\text { - Orderly Expressive } \\
\text { Form/Shape } \\
\text { - Random Grid }\end{array}$ \\
\hline Orthografik & $\begin{array}{l}\text { - Straight lines } \\
\text { - Proportion } \\
\text { - Shapes }\end{array}$ & $\begin{array}{l}\text { - Basic Geometric } \\
\text { - Partly Contrast }\end{array}$ \\
\hline $\begin{array}{l}3 D \\
\text { (isometric \& } \\
\text { perspective) }\end{array}$ & $\begin{array}{l}\text { - Straight lines } \\
\text { - Horizon } \\
\text { - (Human) proportion }\end{array}$ & $\begin{array}{l}\text { - Simplify Geometry } \\
\text { - Dramatic view approach } \\
\text { - Spacy Contrast } \\
\text { - Partly Details }\end{array}$ \\
\hline Urbanscape & $\begin{array}{l}\text { - Horizon } \\
\text { - (Zone) proportion } \\
\text { - Basic perspective }\end{array}$ & $\begin{array}{l}\text { - Compositional } \\
\text { Geometric Simplicity } \\
\text { - Dramatic aerial view } \\
\text { approach } \\
\text { - Partly Contrasity } \\
\text { - Partly Details }\end{array}$ \\
\hline
\end{tabular}

Source: Budiman,2020

\section{Conclusion}

The implementation of the freehand drawing method that processes the elements of expression as described in the application of the methodology in previous paragraphs is clearly answered the research questions. First, freehand drawing practices that are both critical and creative practises which awakens and free up ideas according to the character of the drawing is absolutely necessary. Creativity is defined as the capacity to produce numerous ideas with the highest level of originality (Soliman, 2017). The freedom to explore line types with its own character, which important part that will be reinforced with contrast effect, the dynamic of compositions, or the dramatic point of view, will help develop the expressive architectural designs.

The next conclusion is the importance of combining the basic skills with aesthetic experiments to produce the required architectural expressions. Aesthetic experiments carried out with several times basic element practice has been shown to produce 
significantly powerful architectural expression. And for the last research questions is that freehand drawing with its characterized and expressive drawing is still required throughout the design process, from the beginning phases such as the observation phase, initial idea, the analysis, exploration phase to the design development stage. Each stage in the design process requires its own character of the basic elements of drawing.

According to the description above, it is very clear that drawing not just an illustration of a design process by the drawing system, but the way of expression of architectural thinking. Drawing activities can guide architects to an understanding of architecture as both constructed and construed. Architects use sketches to test out, change and add to their ideas. Many students do not realize how much creative wealth lies hidden inside them, and freehand drawing reveals the secret of design. (Meuser, 2017). Freehand drawing or sketching is defined as a way of visualizing a mental idea. Improving the sketching abilities of student designers is, therefore, a fundamental part of design education (Mumcu \& Görkem ÖZKAN, 2018).

The other important is, by the drawing, it will show the whole process of architectural design thinking with all strong identities of the design idea. Bright thinking is always supported by complete reading, and expressive inspiration is certainly also supported by deep observation and creative experimentation. In the increasingly strong pressure of digital visual processes nowadays that tend to generate stereotypical ideas, architectural freehand drawing has a great opportunity to produce understanding and expressive design results, which are rooted in a strong sense of identity of the design idea. This is why I was happy when the "death of the pencil," proclaimed in the early 1990s by Alan Fletcher on the pages of the magazine Domus, never came. (Bellardi, 2014). And last but not least, the other role of drawing in architecture education is that thinking through drawing courses and workshops provide opportunities to develop innovative, collaborative teaching practices and future research initiatives (Kantrowitz et al., 2017).

\section{References}

Albo, L., \& Hernandez-Leo, D. (2019). Cocreating a web-based visual representation model for authoring blended learning designs. Interaction Design and Architecture(S), 42, 164-182.

Allen, Laura (2016), Drawing Future, Speculation in Contempary Drawing For Art and Architecture, UCL Press, London

Brew, A. C. (2015). Learning to draw : an active perceptual approach to observational drawing synchronizing the eye and hand in time and space (Issue January). The University of the Arts London (Thesis).

Budiman, H., Numan, I., \& Idham, N. C. (2020). From Observing to Imagining the Opportunity of Freehand Drawing in Digital Era. EduARCHsia Proceedings 2019, 187-193. https://doi.org/10.2991/ aer.k.200214.029

Crowe, N. \& Laseau, P. (2012), Visual Note For Architects and Designers, 2nd editions, John Wiley \& Sons, Inc. New Jersey

Herr, C. M. (2015). Action Research as a Research Method in Architecture and Design. Journal Design Studies, 1(1). https://journals.isss.org/index.php/ proceedings59th/article/view/2586

Hoffmann, V. (2010). (2010). Giotto And Renaissance Perspective. Nexus Network Journal, 12(1). https://link.springer.com/ article/10.1007/s00004-010-0015-7

Hong, S. W., Lee, S. Y., \& Lee, J. S. (2016). Incongruent aesthetic preferences in design collaboration: An enabler or barrier for novelty and appropriateness?. Journal of Asian Architecture and Building Engineering, 15(1), 81-88. https://doi. org/10.3130/jaabe.15.81

Kantrowitz, A., Fava, M., \& Brew, A. (2017). Drawing Together Research and Pedagogy. Art Education, 70(April), 50-60. https://doi. org/10.1080/00043125.2017.1286863

Laseau, P. (2001), Graphic Thinking for Architect and Designer, John Wiley \& Sons, Inc., New York

Lee, J. Y. (2014). Phenomenological interpretation of the experience of nature in the works of Le Corbusier. Journal of Asian Architecture and Building Engineering, 13(1), 33-40. https://doi.org/10.3130/ jaabe. 13.33

Mäkelä, M., Nimkulrat, N., \& Heikkinen, T. (2013). Editorial / Drawing as a Research 
Tool: Making and understanding in art and design practice. Studies in Material Thinking, 10 (The Art of Research), 1-16. https://www.researchgate.net/ publication/277308776\%0ADrawing

Mao, X. (2019). Evidence of Cognitive Chunking in Freehand Sketching during Design Ideation. Journal Design Studies, 67(March), 0-28. https://www. sciencedirect.com/science/article/pii/ S0142694X19300857

Meuser, N. (2017). 10 Essential Freehand Drawing Exercises for Architects. ArchDaily 2008-2021, 1-7. https://www.archdaily. com/801871/10-essential-freehanddrawing-exercises-for-architects

Moran, L. ( 2013) What is Drawing ? Irish Museum Modern Art, Dublin

Mumcu, S., \& Görkem ÖZKAN, D. (2018). Design As A Conversation With Lines: "Sketching And Free-Hand" Course Experiences. April. http://dergipark.gov.tr/ gujsb

Orthel, B. D., \& Day, J. K. (2016). Processing Beyond Drawing: A Case Study Exploring Ideation for Teaching Design. SAGE Open Journal,6(3). https://doi. org/10.1177/2158244016663285

Pekol, B. (2005). Late Medieval Architectural and Micro Architectural Drawings A Hidden Order?. Courtauld Institute of Art, London (Thesis).

Pilsitz, M. (2017). Drawing and Drafting in Architecture Architectural History as a Part of Future Studies. Periodica Polytechnica Architecture, 48(1), 72-78. https://doi. org/10.3311/ppar.11310

Serra, J., Torres, A., Llopis, J., Giménez, M., \& García, Á. (2015). Forget what you have Learned: Spontaneous Drawing for the Genesis of Architecture. Procedia - Social and Behavioral Sciences, 191(May), 1128-1134. https://doi.org/10.1016/j. sbspro.2015.04.381

Smith, K. S. ( 2005 ), Architect Drawings : A Selection of Sketches by World Famous Architects Through History, Architectural Press An imprint of Elsevier, Oxford.

Soliman, A. M. (2017). Appropriate teaching and learning strategies for the architectural design process in pedagogic design studios. Frontiers of Architectural Research, 6(2), 204-217. https://doi. org/10.1016/j.foar.2017.03.002 